\title{
Validity and Reliability of a Wearable Insole Pressure System for Measuring Gait Parameters to Identify Safety Hazards in Construction
}

\author{
Maxwell Fordjour ANTWI-AFARI ${ }^{\mathrm{a}}$, Heng $\mathrm{LI}^{\mathrm{b}}$, JoonOh $\mathrm{SEO}^{\mathrm{c}}$, Shahnawaz ANWER ${ }^{\mathrm{d}}$, Sitsofe \\ Kwame YEVU ${ }^{\mathrm{e}}$, Zezhou WU
}

${ }^{a}$ Lecturer, Department of Civil Engineering, College of Engineering and Physical Sciences, Aston University, B4 7ET, Birmingham, United Kingdom, E-mail: m.antwiafari@aston.ac.uk

${ }^{\mathrm{b}}$ Chair Professor, Department of Building and Real Estate, Faculty of Construction and Environment, The Hong Kong Polytechnic University, Room No. ZS734, Hung Hom, Kowloon, Hong Kong Special Administrative Region, E-mail: heng.li@ polyu.edu.hk

${ }^{c}$ Assistant Professor, Department of Building and Real Estate, Faculty of Construction and Environment, The Hong Kong Polytechnic Univ., Room No. ZN742, Hung Hom, Kowloon, Hong Kong Special Administrative Region. E-mail: joonoh.seo@ polyu.edu.hk

${ }^{\mathrm{d}} \mathrm{PhD}$ Student, Department of Building and Real Estate, Faculty of Construction and Environment, The Hong Kong Polytechnic University, Room No. ZN1002, Hung Hom, Kowloon, Hong Kong Special Administrative Region, E-mail: shahnawaz.anwer@ connect.polyu.hk

${ }^{e} \mathrm{PhD}$ Student, Department of Building and Real Estate, Faculty of Construction and Environment, The Hong Kong Polytechnic University, Room No. ZN712, Hung Hom, Kowloon, Hong Kong Special Administrative Region, E-mail: sitsofe-k.yevu@connect.polyu.hk

${ }^{\mathrm{f}}$ Assistant Professor, Department of Construction Management and Real Estate, College of Civil and Transportation Engineering, Shenzhen University, Shenzhen 518000, China, Email: wuzezhou@szu.edu.cn

\section{*Corresponding author:}

Dr Maxwell Fordjour Antwi-Afari

Lecturer, Department of Civil Engineering, College of Engineering and Physical Sciences, Aston University, B4 7ET, Birmingham, United Kingdom. E-mail: m.antwiafari@aston.ac.uk 


\begin{abstract}
Purpose - Construction workers are frequently exposed to safety hazards on sites. Wearable sensing systems (e.g., wearable inertial measurement units (WIMUs), wearable insole pressure system (WIPS)) have been used to collect workers' gait patterns for distinguishing safety hazards. However, the performance of measuring WIPS-based gait parameters for identifying safety hazards as compared to a reference system (i.e., WIMUs) has not been studied. Therefore, this study examined the validity and reliability of measuring WIPS-based gait parameters as compared to WIMU-based gait parameters for distinguishing safety hazards in construction.
\end{abstract}

Design/methodology/approach - Five fall risk events were conducted in a laboratory setting and the performance of the proposed approach was assessed by calculating the mean difference (MD), mean absolute error (MAE), mean absolute percentage error (MAPE), root mean square error (RMSE), and intraclass correlation coefficient (ICC) of five gait parameters.

Findings - Comparable results of MD, MAE, MAPE, and RMSE were found between WIPSbased gait parameters and the reference system. Furthermore, all measured gait parameters had validity ( $\mathrm{ICC} \geq 0.751)$ and test-retest reliability ( $\mathrm{ICC} \geq 0.910$ ) closer to 1 , indicating a good performance of measuring WIPS-based gait parameters for distinguishing safety hazards.

Research limitations/implications - Overall, this study supports the relevance of developing a WIPS as a non-invasive wearable sensing system for identifying safety hazards on construction sites, thus highlighting the usefulness of its applications for construction safety research.

Originality - This is the first study to examine the performance of a wearable insole pressure system for identifying safety hazards in construction.

Keywords: Gait Parameters; Non-fatal fall injuries; Safety hazards; Wearable inertial measurement unit; Wearable insole pressure system

Paper type: Research paper 


\section{Introduction}

The construction industry is widely recognized as one of the most hazardous occupations with a high risk of developing fatalities and non-fatal fall injuries (Earnest and Branche, 2016). In the United States, more than 700 fatal and 200,000 non-fatal injuries are reported every year in the construction industry (Bureau of Labor Statistics, 2017). Specifically, slips, trips, and loss of balance events are classified as the main cause of non-fatal fall injuries (Lipscomb et al., 2006; Antwi-Afari and Li, 2018g; Antwi-Afari et al., 2020b). Non-fatal fall injuries may not only result to work absenteeism, high insurance premiums, but also lead to loss of workers' productivity and workers' disabilities (Earnest and Branche, 2016). Given these adverse effects, it is essential to implement effective approaches to prevent non-fatal fall injuries among construction workers.

Previous studies have demonstrated several traditional approaches to identify safety hazards among construction workers (Zou and Zhang, 2009; Teizer et al., 2010; Han and Lee, 2013). Selfreported approaches are usually achieved by manual inspections that are performed by safety managers. Examples include accident reports, safety checklists, and safety training (Zou and Zhang, 2009; Rozenfeld et al., 2010). Although they are useful for safety hazard identification, they are usually biased, time-consuming, and involve imprecise procedures (Van Eerd et al., 2009). Other researchers have utilized vision-based approaches (e.g., depth cameras) to analyze workers' motions to identify safety hazards (Ray and Teizer, 2012; Han and Lee, 2013; Kim et al., 2017; Yuan et al., 2017). Kim et al. (2017) proposed a vision-based hazard avoidance system that proactively informs workers of potentially dangerous situations. It was reported that the proposed system can mitigate hazards and improve construction site safety. Despite their usefulness for enhancing safety hazard identification, vision-based approaches are limited due to constrained 
light conditions, occlusion, and misrepresentation of real-time motion conditions (Valero et al., 2017). Collectively, these traditional approaches are limited to the performance of safety hazard identification on construction sites.

Thanks to the recent development of wearable sensing technologies, safety hazard identification has become increasingly applicable to construction environments. Wearable inertial measurement units (WIMUs) are one of the potential approaches used to identify safety hazards by collecting workers' bodily responses or gait patterns during the existence of safety hazards (Akhavian and Behzadan, 2016; Yang et al., 2017; Yang et al., 2019). Since non-fatal fall injuries are often caused by extrinsic risk factors between the human foot and surface condition, workers' gait movements contain valuable information for identifying safety hazards (Antwi-Afari and Li, 2018g). As such, the feasibility of collecting workers' gait movements measured by using WIMUs has been extensively studied (Kim et al., 2016; Yang et al., 2017; Yang and Ahn, 2019).

Although WIMUs have potential applications, multiple WIMUs are needed to be attached to a worker's body parts (e.g., ankle, waist) to collect gait patterns for identifying safety hazards. Accordingly, attaching multiple WIMUs to the skin surfaces may not only lead to workers' discomforts but also may reduce workers' productivity (Antwi-Afari and Li, 2018g). In addition, WIMUs are difficult to acquire ground reaction force data when workers use their feet as the main support of the whole body (Antwi-Afari et al., 2018f; Antwi-Afari et al., 2020a). Moreover, they are intrusive and require indirect forms of attachments such as straps, belts, or other accessories to prevent detachment of sensors from the body when performing a given task. To address the given limitations, previous studies proposed a non-invasive approach to identify the loss of balance 
(Antwi-Afari et al., 2018e), recognize workers' activities and assess ergonomic risks (Antwi-Afari et al., 2020a) and measure the fall risk (Antwi-Afari and Li, 2018g) by using a wearable insole pressure system (WIPS). However, the performance of WIPS-based gait parameters compared to WIMU-based gait parameters to identify safety hazards has not been explored.

To address this research gap, the objective of this study was to examine the validity and reliability of WIPS-based gait parameters for distinguishing safety hazards as compared to WIMU-based gait parameters (i.e., reference system). To do this, a series of experiments were conducted in a simulated laboratory environment to test the performance of the proposed approach. The results of the current study could confirm the usefulness of WIPS-gait parameters for identifying safety hazards on construction sites. The main contribution of this study relies on examining the performance of a WIPS for identifying safety hazards in construction.

\section{Literature review}

Safety hazard identification is the first step in preventing non-fatal injuries in the construction industry. Previous studies have utilized several traditional methods for safety hazard identification in construction. Examples are job-hazard analyses (Rozenfeld et al., 2010), safety checklists (Fang et al., 2004), and safety training (Albert et al., 2014a). Although these previous studies offered insight to preventing the risk of fall injuries, however, safety hazard identification was mostly

performed by manual inspection by safety managers. In addition, they are limited by the availability of resources (e.g., safety manager), and different levels of expert judgments (Albert $e t$ al., 2014a, Albert et al., 2014b). 
To overcome existing approaches, numerous advanced sensing technologies (Antwi-Afari et al., 2019a; Edirisinghe, 2019) have been proposed to enhance safety hazard identification. Examples include building information modeling (Zhang et al., 2013), global positioning system (GPS) (Wang and Razavi, 2016), RFID (Teizer et al., 2010), Bluetooth sensing technology (Park et al., 2015), and vision-based techniques (Han and Lee, 2013). However, the applications of visionbased techniques are not only limited due to the sensing range of a camera, visual occlusions, and misrepresentation but also require a direct line of sight is to register the movements (Valero et al., 2017; Kong et al., 2018). Despite their efficient performance to identify safety hazards on construction sites, the major drawback of most of these sensing technologies is that safety managers must still apply manual observation to identify safety hazards.

The development of wearable sensing technologies (e.g., WIMUs) has recently gained attention to enable the collection and analysis of workers' bodily responses or gait patterns to prevent workrelated musculoskeletal disorders (WMSDs), physical demands, and fall injuries (Akhavian and Behzadan, 2016; Yang et al., 2017; Antwi-Afari et al., 2018a; Yang et al., 2019). Yang et al. (2019) evaluated the accuracy of WIMUs-based gait parameters to distinguish hazardous conditions. These authors found a 6.48 mean absolute percentage error in a non-hazard condition which revealed the validity of gait parameter for distinguishing hazardous conditions compared to the reference motion tracking system. Accordingly, the findings from previous studies have provided valuable insights for monitoring human gait analysis to assess fall injuries not only in construction environments (Kim et al., 2016; Yang and Ahn, 2019; Yang et al., 2019) but also in clinical, sport and rehabilitation settings (Leardini et al., 2014; Norris et al., 2014; Shull et al., 2014). 
While these previous studies had shown significant efforts in assessing the risk of non-fatal fall injuries by using WIMUs, they are however limited because they: (1) require the use of multiple WIMUs to be attached to the subject's lower body parts (e.g., ankle) for ambulatory gait analysis (Antwi-Afari, 2019; Antwi-Afari et al., 2019a); (2) can only capture thresholds such as the magnitude of angular velocity and acceleration signals as the main sensor data streams to identify safety hazards. However, such thresholds diminish the automation potential of these approaches (Yang and Ahn, 2019); and (3) are intrusive and attaching WIMUs to the skin surfaces may not only lead to workers' discomforts and inconveniences but also may reduce construction workers' productivity (Antwi-Afari and Li, 2018g; Antwi-Afari et al., 2020a).

To address these limitations, previous studies proposed a WIPS to analyze the changes in biomechanical gait stability parameters (Antwi-Afari and $\mathrm{Li}, 2018 \mathrm{~g}$ ), to detect and classify awkward working postures (Antwi-Afari et al., 2018f), and to detect and classify loss of balance events (Antwi-Afari et al., 2018e). Taken together, previous studies had indicated that foot plantar pressure distribution data captured by using a WIPS can not only allow safety managers to identify the risk for developing WMSDs, but also minimize the risk of non-fatal fall injuries among construction workers. Notably, gait parameters (e.g., stride time, stride length, swing time) are particularly useful measurements for identifying safety hazards to minimize the risk of non-fatal fall injuries on construction sites (Yang et al., 2019). This could be explained by the fact that nonfatal fall injuries are often initiated by external environmental surface conditions between a worker's foot and surface condition (Kim et al., 2016; Antwi-Afari and Li, 2018g). As such, continuous monitoring of workers' gait movements could provide valuable insight for safety hazard identification to prevent the occurrence of non-fatal fall injuries among construction 
workers (Antwi-Afari et al., 2018e; Yang et al., 2019). Previous studies in rehabilitation and clinical settings have demonstrated the validity of collecting WIPS-based gait parameters for assessing the risk of non-fatal fall injuries during patients' daily living activities such as walking (Crea et al., 2014; Braun et al., 2015). However, the performance of measuring WIPS-based gait parameters for identifying safety hazards in the construction environment has not yet been explored. To evaluate the performance of WIPS-based gait parameters for identifying safety hazards in construction, this study compared WIPS-based parameters to WIMUs-based gait parameters. Since the existence of safety hazards on construction sites could lead to the occurrence of non-fatal fall injuries among construction workers, the performance of collecting WIPS-based gait parameters could provide great potential for identifying safety hazards.

\section{Research methodology}

\subsection{Participants}

Five healthy male participants between the age of 30 and 40 years were recruited to participate in this current study (age: $32.8 \pm 1.92$ years; height: $1.7 \pm 0.03 \mathrm{~m}$; and weight: $70.8 \pm 3.96 \mathrm{~kg}$ ). None of the participants had any history of physical or neurological conditions that might interfere with their respective gait movements. All the participants gave their written informed consent and the experimental procedures were approved by the Human Subject Ethics Subcommittee of the Hong Kong Polytechnic University.

\subsection{Experimental set-up}

An OpenGo system (Moticon SCIENCE Sensor Insole GmbH, Munich, Germany) (Fig. 1a), which consists of 16 capacitive pressure sensors, a 3-axis gyroscope (MEMS LSM6DSL, ST 
Microelectronics), a 3-axis accelerometer for each sensor insole was used for data collection. Pressure sensors have a range, resolution, and hysteresis of 0 to $50.0 \mathrm{~N} / \mathrm{cm}^{2}, 0.25 \mathrm{~N} / \mathrm{cm}^{2}$, and $\leq$ $1 \%$, respectively. Manufacturer's guidelines indicate that no calibration is needed within its production lifetime. The acceleration and angular rate ranges are between $\pm 16 \mathrm{~g}$ and $\pm 2000 \mathrm{dps}$, respectively. Each sensor insole contains on-board memory storage (16 MB) and a coin cell rechargeable of $3.7 \mathrm{~V} \pm 0.4 \mathrm{~V}$ power supply. It uses a Bluetooth low energy 5.0 for wireless transmission within a wireless range of $\geq 5.0 \mathrm{~m}$ and bandwidth of $54 \mathrm{kB} / \mathrm{s}$. The sampling frequency used in this study was 50Hz (Antwi-Afari et al., 2019c; Antwi-Afari et al., 2020b).

Two WIMUs (YEI 3-Space Sensor ${ }^{\mathrm{TM}}$ Bluetooth, Yost Labs, Inc., Portsmouth, Ohio, USA) (Fig. 1b) were attached to the participants' ankle for data collection. It integrates triaxial accelerometer, gyroscope, and compass sensors in conjunction with advanced processing and on-board quaternion-based orientation filtering algorithms to determine orientation relative to an absolute reference in real-time. It has an integrated $2.4 \mathrm{GHz}$ Bluetooth v2.0 EDR Class 1 wireless interface which allows high performance at a range up to 300 '. It also has an integrated Lithium-Polymer battery and charge control which allow a battery life of $5+$ hours at full performance. The data collected from the WIMUs was sampled at 50Hz.

\subsection{Experimental design and procedure}

The current study adopted a randomized crossover study design in a single testing session. Prior to the testing session, the experimental procedure was fully explained to each participant. Afterward, all participants provided their written informed consent and demographic data. This study was conducted in a laboratory setting to test fall risk events which may lead workers to 
develop non-fatal fall injuries on construction sites (Fig. 1). In order to simulate these fall risk events to emulate real-world occurrence of non-fatal fall accidents on construction sites, each participant could watch representative videos of non-fatal fall accidents that had occurred on construction sites. Subsequently, they were instructed to practice each fall risk event. In addition, each participant wore a pair of safety boots, safety harness, and a hard hat during the testing session. During data collection, each participant had to walk on a pre-designed path with installed safety hazards at their own comfortable pace. Our ultimate goal was to conduct similar experimental events while utterly preventing our participant from experiencing any unexpected non-fatal fall injuries along the path with installed safety hazards on the floor surface.

In the present study, four hazardous events were tested at a specific location (i.e., $4 \mathrm{~m}$ ) during the testing session (Fig. 1). They include (1) a slippery hazard (i.e., a low-density polyethene) that may cause a slip event (Fig. 1d); (2) an obstacle hazard (i.e., a concrete brick measuring $20 \mathrm{~cm} \times$ $9 \mathrm{~cm} \times 6 \mathrm{~cm}$ height) that may cause a trip event (Fig. 1e); and (3) an uneven surface hazard (i.e., a wooden platform with $20 \mathrm{~cm}$ height) that may cause an unexpected step-down event (Fig. 1f); and (4) a load hazard (i.e., $5 \mathrm{Kg}$ in a wooden box-measuring $30 \times 30 \times 25 \mathrm{~cm}$ with dumbbell weights) that may cause a fall on the same level event (Fig. 1g). Notably, these safety hazards were used because they are often exposed to workers on construction sites and may create abnormal patterns in workers' gait movement (Antwi-Afari and Li, 2018g). In addition, the above-mentioned safety hazards have been demonstrated to cause non-fatal fall injuries on construction sites (Bentley et al., 2006; Lipscomb et al., 2006) and other occupational environments (Gauchard et al., 2001; Yoon and Lockhart, 2006). Moreover, it has been reported that carrying a load may lead to nonfatal fall injuries (Liu and Lockhart, 2013). 
Five fall risk events were conducted in this current study (Fig. 1). They are (1) normal walk (i.e., baseline) event without any safety hazard (Fig. 1c); (2) a slip event induced by a slippery hazard (Fig. 1d); (3) a trip event induced by an obstacle hazard (Fig. 1e); (4) an unexpected step-down event induced by an uneven surface hazard (Fig. 1f); and (5) a load-carrying event without a hazard (Fig. 1g). Each participant performed ten repeated trials of each fall risk event. The sequence of conducting these fall risk events was randomized utilizing a random number generator. The participants were allowed to rest for 5 minutes between two successive trials to prevent fatigue. In all experimental events, the participants did not have prior knowledge of the safety hazards but were told that there could be unexpected conditions during normal gait. For a participant not to recognize the safety hazards on the floor surface, the lights in the laboratory were dimmed and the participants were instructed to look straight ahead during the testing sessions. The entire experiments were recorded using a video camcorder, and the video was time-synchronized with both the WIMU and WIPS data. Also, the video data were used as reference data for exhibiting the different types of safety hazards during a normal gait movement. 


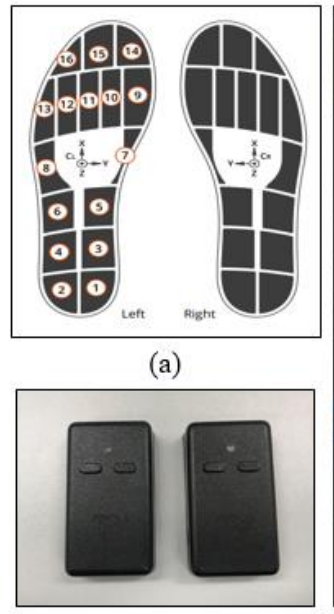

(b)

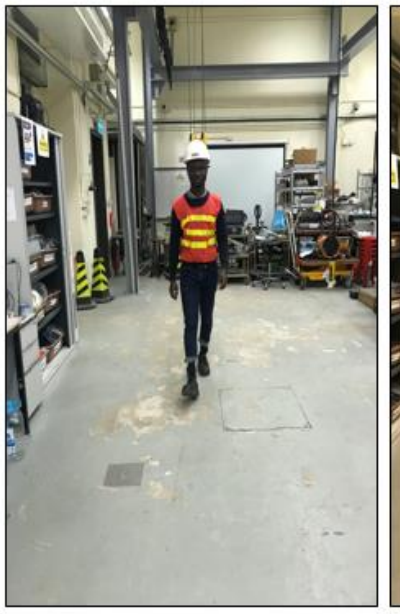

(c)

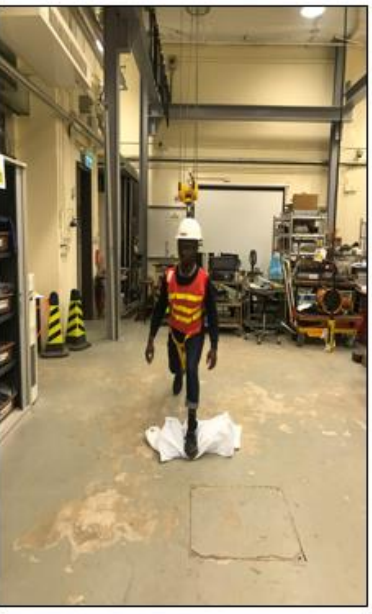

(d)

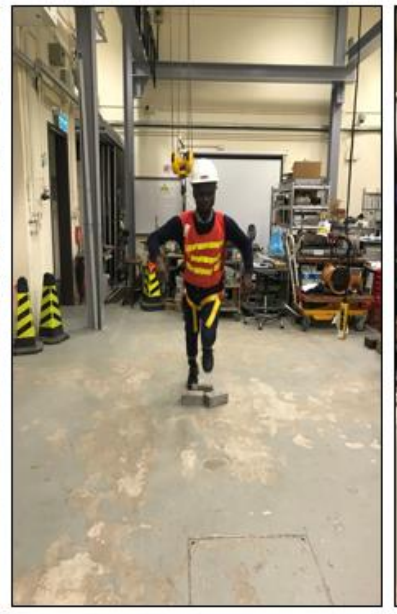

(e)

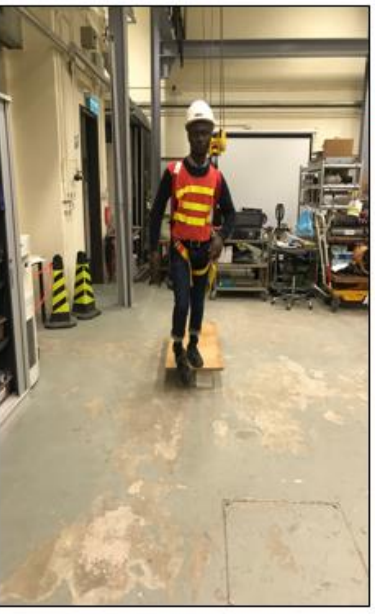

(f)

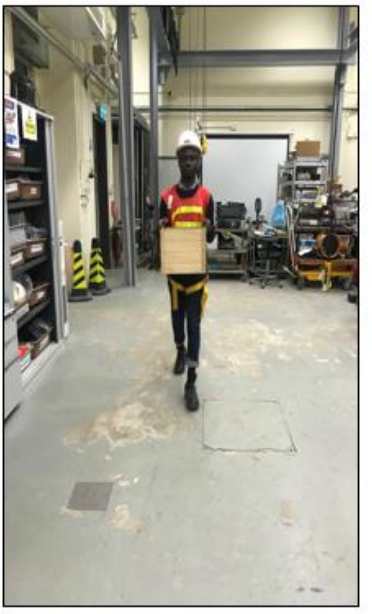

(g)

Fig. 1. Laboratory experimental setup: (a) Wearable insole pressure system; (b) Wearable inertial measurement unit; (c) Normal walk; (d) Slip event; (e) Trip event; (f) Unexpected step-down event; (g) Carrying load event. 


\subsection{Data processing and analysis}

Gait event detection is the first crucial step to compute gait parameters. Since a normal gait is a cyclic movement of the foot, the heel strike and toe-off events need to be detected to compute gait parameters. Foot plantar pressure distribution data provide unique pressure patterns that aided in the detection of gait events. Notably, the sampling frequency was set at a rate of $50 \mathrm{~Hz}$ (i.e., 50 data samples per second) and each fall risk event was completed in an average of $10 \mathrm{~s}$. Consequently, a single experimental trial of a fall risk event (e.g., slip) contains $500(=50 \times 10)$ data samples. Since five participants were recruited to perform 10 repeated trials of each fall risk event, a total of $125,000(=500 \times 5$ participants $\times 10$ trials $\times 5$ fall risk events $)$ data samples were analyzed. Although previous validation studies performed different experimental protocols (Braun et al., 2015; Loiret et al., 2019), the number of data samples and participants is comparable to the current study, which enabled the choice of statistical analyses.

In this study, a gait cycle was defined as the gait patterns between consecutive heel strikes of the same foot (Hausdorff et al., 1998). To detect heel strike and toe-off events during a gait cycle, the average pressure was calculated at the heel and toe foot regions. From the four main anatomical foot regions (Choi et al., 2015), toe region of the foot consists of sensors 14 to 16, whilst the heel region of the foot comprises of sensors 1 to 4 . Since plantar pressure patterns were collected bilaterally during the experiments, the average pressure sensors from either the left or right foot were used for detecting gait events. Figure 2 shows an example of the average plantar pressure sensor amplitude of each fall risk event that was used to compute gait parameters. As shown in Fig. 2, each fall risk event exhibited unique plantar pressure patterns, thus enabling the understanding of gait event detection to compute gait parameters. 
On the other hand, the angular velocity data from the WIMUs were used for gait event detection (Fig. 2), which is mainly the heel strike and toe-off events. This study adopted the changes in pitch of angular velocity for computing WIMU-based gait parameters because they are insensitive to the influence of gravity, attachment locations, and provide vital performance detection of gait events (Aminian et al., 2002). During data collection, the pitch of angular velocity data showed the lowest point before the peak and the lowest point after the peak, representing the toe-off event and the heel strike event, respectively. The coordinates of the toe-off event and the heel strike event are subsequently used to define a gait cycle. Based on a gait cycle, both WIPS-based gait parameters and WIMU-based gait parameters can be successfully computed. Since the data collection was conducted with the same sampling frequency, the data synchronization between the WIPS and WIMUs was performed based on the video data and the collected timestamps. 

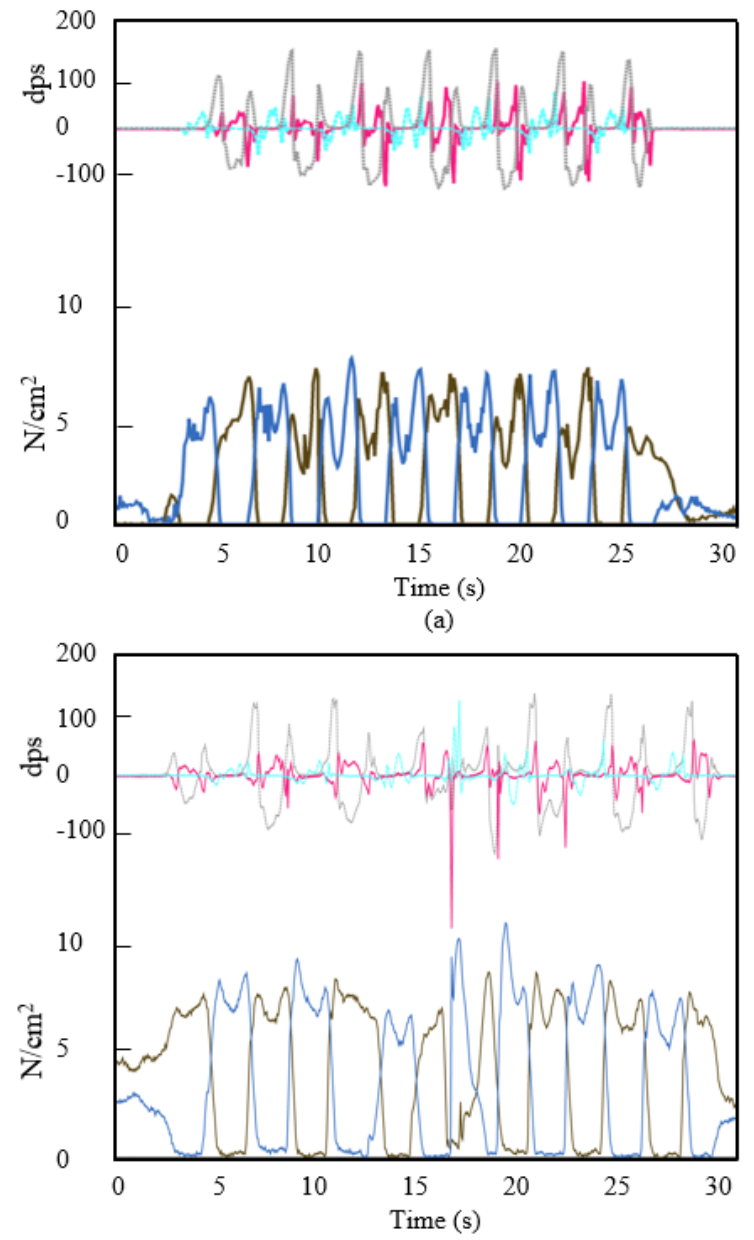

(d)
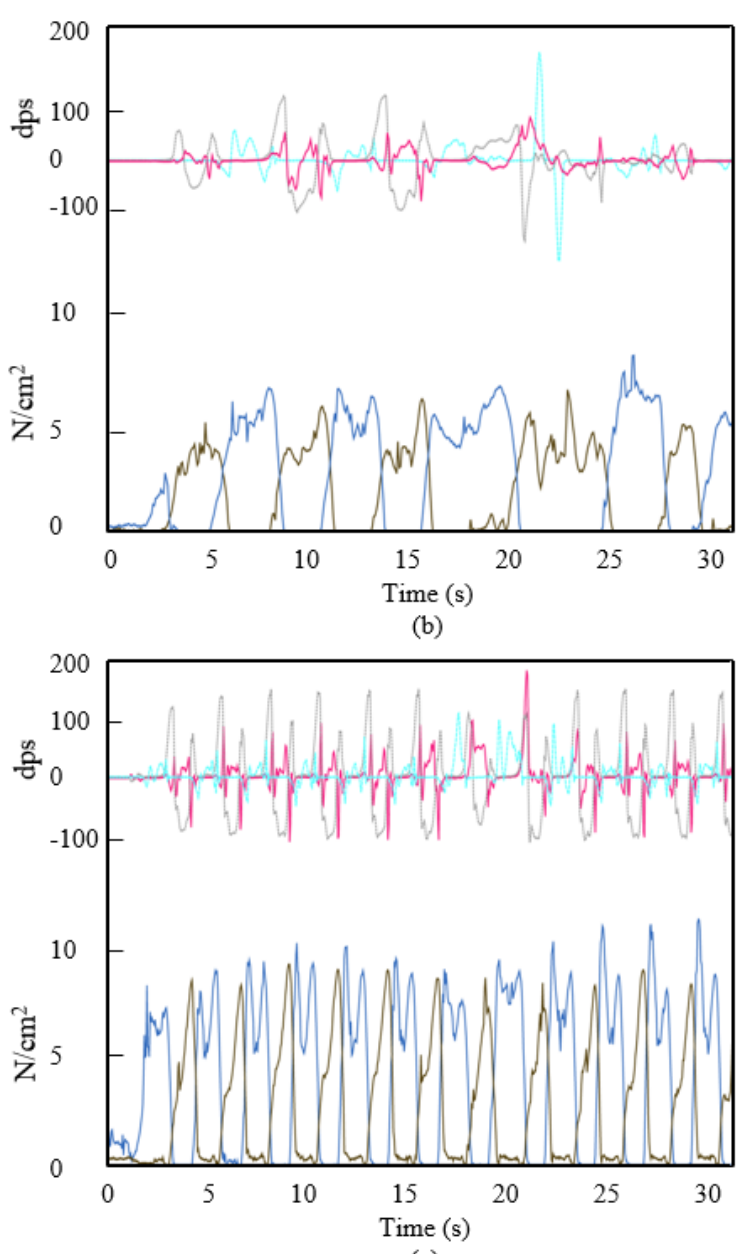

(e)

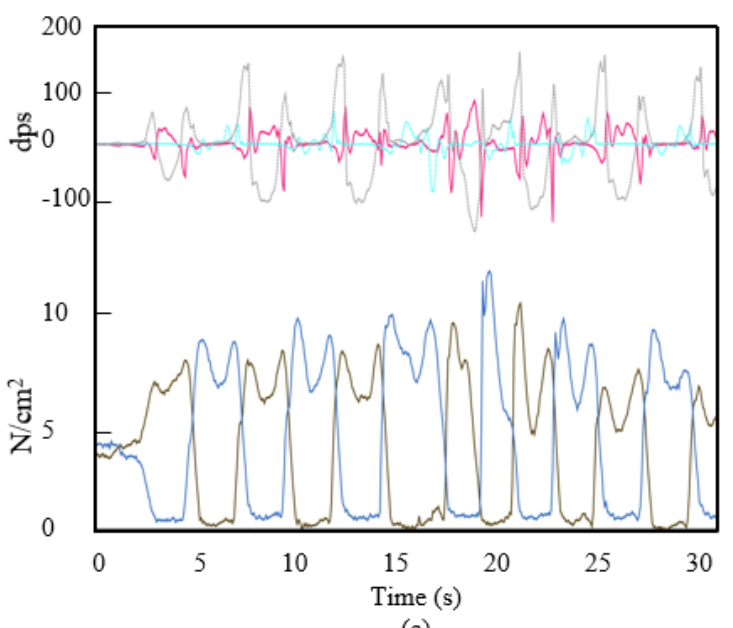

Angular velocity $X$

Angular velocity $Y$

Angular velocity $Z$

\section{Left foot}

Right foot

Fig. 2. Average plantar pressure sensor amplitude and angular velocity during each fall risk event: (a) Normal walk; (b) Slip; (c) Trip;

(d) Unexpected step-down; and (e) Carrying load. 
Initially, this study computed five gait parameters based on gait event detection from the two wearable measurement systems. They are stride time $(S T)$, stride length $(S L)$, swing time $(S w P)$, stance time (StP), and single support time (SST). Table 1 depicts the computed gait parameters with their respective equations.

Table 1. Gait parameters

\begin{tabular}{|c|c|c|}
\hline Gait parameters & Equations & \\
\hline \multirow[t]{2}{*}{ Stride time $(S T),(\mathrm{s})$} & $S T_{L}=t\left(L H S_{i+1}\right)-t\left(L H S_{i}\right)$ & (1) \\
\hline & $S T_{R}=t\left(R H S_{i+1}\right)-t\left(R H S_{i}\right)$ & $(2)$ \\
\hline \multirow[t]{4}{*}{ Stride length $(S L),(\mathrm{m})$} & $S L_{I}=\frac{\text { Walking Speed } \times S T_{L}}{}$ & (3) \\
\hline & ${ }^{J L}-\frac{H e i g h t}{H}$ & \\
\hline & Walking Speed $\times S T_{R}$ & \\
\hline & $S L_{R}=\frac{\text { Height }}{\kappa}$ & $(4)$ \\
\hline \multirow[t]{4}{*}{ Swing time $(S w P)(\%)$} & $t\left(L H S_{i+1}\right)-t\left(L T O_{i}\right)$ & \\
\hline & $\% S W P_{L}=\overline{t\left(L H S_{i+1}\right)-t\left(L H S_{i}\right)} \times 100 \%$ & (5) \\
\hline & $0 S_{w}=\frac{t\left(R H S_{i+1}\right)-t\left(R T O_{i+1}\right)}{100 \%}$ & \\
\hline & $\% S W P_{R}=\frac{t\left(R H S_{i+1}\right)-t\left(R H S_{i}\right)}{t} \times 100 \%$ & (6) \\
\hline \multirow[t]{4}{*}{ Stance time $(S t P)(\%)$} & $\% S t P_{x}=\frac{t\left(L T O_{i}\right)-t\left(L H S_{i}\right)}{}$ & (7) \\
\hline & $\% S C P_{L}=\overline{t\left(L H S_{i+1}\right)-t\left(L H S_{i}\right)} \times 100 \%$ & (1) \\
\hline & $0 S+P=\frac{t\left(R T O_{i+1}\right)-t\left(R H S_{i}\right)}{100 \%}$ & (8) \\
\hline & $0 \Delta R_{R}-\overline{t\left(R H S_{i+1}\right)-t\left(R H S_{i}\right)}$ & (0) \\
\hline \multirow[t]{4}{*}{ Single support time $(S S T)(\%)$} & $t\left(R H S_{i+1}\right)-t\left(R T O_{i+1}\right)$ & \\
\hline & $\overline{t\left(L H S_{i+1}\right)-t\left(L H S_{i}\right)} \times 100 \%$ & (9) \\
\hline & $t\left(L H S_{i+1}\right)-t\left(L T O_{i}\right)$ & \\
\hline & $\% S S T_{R}=\frac{t\left(R H S_{i+1}\right)-t\left(R H S_{i}\right)}{t} \times 100 \%$ & $(10)$ \\
\hline
\end{tabular}

Note: $S T_{L}=$ Stride time of the left foot; $S T_{R}=$ Stride time of the right foot; $t\left(L H S_{i+1}\right)=$ Time of the $(i+1)^{t h}$ heel strike event of the left foot; $t\left(R H S_{i+1}\right)=$ Time of the $(i+1)^{t h}$ heel strike event of the right foot; $t\left(L H S_{i}\right)=$ Time of the $i^{t h}$ heel strike event of left foot; $t\left(R H S_{i}\right)=$ Time of the $i^{\text {th }}$ heel strike event of right foot; $S L_{L}=$ Normalized stride length of the left foot; $S L_{R}=$ Normalized stride length of the right foot; $\% S w P_{L}=$ Percentage of the swing phase of the left foot; $\% S w P_{R}=$ Percentage of the swing phase of the right foot; $\% S t P_{L}=$ Percentage of the stance phase of the left foot; $\% S t P_{R}=$ Percentage of the stance phase of the right foot; $t\left(L T O_{i+1}\right)=$ 
Time of the $(i+1)^{t h}$ toe-off event of the left foot; $t\left(R T O_{i+1}\right)=$ Time of the $(i+1)^{t h}$ toe-off event of the right foot; $t\left(L T O_{i}\right)=$ Time of the $i^{t h}$ toe-off event of the left foot; $t\left(R T O_{i}\right)=$ Time of the $i^{\text {th }}$ toe-off event of the right foot; \%SST $=$ Percentage of single support time of the left foot; $\% S S T_{R}=$ Percentage of single support time of the right foot.

\subsection{Statistical analysis}

First, the Shapiro-Wilk normality test was conducted to analyze the normality of each gait parameter. Since all gait parameters were normally distributed $(p>0.05)$, paired sample $t$-Test was used to investigate the significant difference between normal gait and each hazardous event. The concurrent validity was analyzed by calculating the mean difference (MD), mean absolute error (MAE), mean absolute percentage error (MAPE), root mean square error (RMSE), and intraclass correlation coefficient (ICC) with 95\% confidence intervals (CI) of WIPS-based gait parameters and WIMU-based gait parameters. For the test-retest reliability, only two randomly selected trials of each participant were used. All statistical analyses were analyzed by the Statistical Package for the Social Science (SPSS) version 20.0 (IBM, USA). Statistical significance was set at $p<0.05$.

$$
\begin{aligned}
& M D=\left|W I M U_{\text {mean }}-W I P S_{\text {mean }}\right| \\
& M A E=\frac{1}{N} \sum_{i=1}^{N}\left|W I M U_{i}-W I P S_{i}\right| \\
& M A P E=\frac{1}{N} \sum_{i=1}^{N} \frac{\left|W I M U_{i}-W I P S_{i}\right|}{W I M U_{i}} \times 100 \\
& R M S E=\sqrt{\frac{1}{N}} \sum_{i=1}^{N}\left(W I M U_{i}-W I P S_{i}\right)^{2}
\end{aligned}
$$


Where, WIMU $U_{\text {mean }}$ and WIPS $S_{\text {mean }}$ are the mean values of each gait parameter from WIMU and WIPS, respectively. WIMU $U_{i}$ and $W I P S_{i}$ are the $i^{\text {th }}$ gait parameter values from WIMU and WIPS, respectively. Lastly, $N$ is the total number of collected data samples.

\section{Results}

Table 2 shows the results of the two-sample $t$-test between normal gait and each hazardous event. The purpose of this analysis was to investigate whether there exists a statistically significant difference of gait parameters captured by each wearable sensing measurement system (i.e., WIMU-based gait parameters or WIPS-based gait parameters) between a normal gait and each hazardous event. With regards to WIMU-based gait parameters, $S T, S L$, and $S w P$ showed significant differences between a normal gait and all hazardous events except the carrying load hazard event (Table 2). These results may indicate that hazardous events such as slip, trip, and unexpected step-down exhibited unique plantar pressure patterns unlike carrying load hazard events. It could also suggest that carrying a load of $5 \mathrm{~kg}$ for a short duration may not cause any adverse effect on participants' gait movements. Similar results were found with WIPS-based gait parameters such as $S T, S L$, and $S w P$ indicating significant differences between normal gait and each hazardous event (Table 2). As shown in Table 2, gait parameters such as StP and SST revealed inconsistent results between a normal gait and each hazardous event either by using a WIMU or WIPS. Ultimately, the results show that either WIMU-based gait parameters or WIPS-based gait parameters such as $S T, S L$, and $S w P$ could achieve similar findings in distinguishing a normal gait and hazardous events such as slip, trip and unexpected step-down. 
Table 2. Results of two-sample $t$-test between normal gait and each hazardous condition

\begin{tabular}{|c|c|c|c|c|c|c|c|c|c|c|c|}
\hline \multirow[t]{2}{*}{ Participants } & \multirow[t]{2}{*}{ Fall risk events } & \multicolumn{5}{|c|}{ WIMU-based gait parameters } & \multicolumn{5}{|c|}{ WIPS-based gait parameters } \\
\hline & & $S T(\mathbf{s})$ & $S L(\mathbf{m})$ & SwP $(\%)$ & StP $(\%)$ & $S S T(\%)$ & $S T(\mathbf{s})$ & $S L(\mathbf{m})$ & SwP $(\%)$ & $\operatorname{StP}(\%)$ & $S S T(\%)$ \\
\hline \multirow[t]{4}{*}{1} & Slip & $x$ & $x$ & $x$ & $x$ & $x$ & $x$ & $x$ & $x$ & $x$ & $x$ \\
\hline & Trip & $x$ & $x$ & $x$ & $\sqrt{ }$ & $\sqrt{ }$ & $x$ & $x$ & $\times$ & $\sqrt{ }$ & $\sqrt{ }$ \\
\hline & Unexpected step-down & $x$ & $x$ & $x$ & $\sqrt{ }$ & $x$ & $x$ & $x$ & $x$ & $x$ & $\sqrt{ }$ \\
\hline & Carrying load & $\times$ & $\times$ & $\times$ & $x$ & $x$ & $\times$ & $\times$ & $\times$ & $x$ & $x$ \\
\hline \multirow[t]{4}{*}{2} & Slip & $x$ & $x$ & $x$ & $x$ & $x$ & $x$ & $x$ & $x$ & $x$ & $x$ \\
\hline & Trip & $x$ & $x$ & $x$ & $x$ & $x$ & $x$ & $x$ & $x$ & $x$ & $\sqrt{ }$ \\
\hline & Unexpected step-down & $x$ & $x$ & $x$ & $\sqrt{ }$ & $\sqrt{ }$ & $x$ & $x$ & $x$ & $\sqrt{ }$ & $\sqrt{ }$ \\
\hline & Carrying load & $\times$ & $\times$ & $\times$ & $\sqrt{ }$ & $\sqrt{ }$ & $\times$ & $\times$ & $\times$ & $\sqrt{ }$ & $\sqrt{ }$ \\
\hline \multirow[t]{4}{*}{3} & Slip & $x$ & $x$ & $x$ & $x$ & $x$ & $x$ & $x$ & $x$ & $x$ & $x$ \\
\hline & Trip & $x$ & $x$ & $x$ & $\sqrt{ }$ & $x$ & $x$ & $x$ & $x$ & $x$ & $x$ \\
\hline & Unexpected step-down & $x$ & $x$ & $x$ & $x$ & $\sqrt{ }$ & $x$ & $x$ & $\times$ & $\sqrt{ }$ & $x$ \\
\hline & Carrying load & $\times$ & $\times$ & $\times$ & $x$ & $\times$ & $\times$ & $\times$ & $\times$ & $x$ & $\times$ \\
\hline \multirow[t]{4}{*}{4} & Slip & $x$ & $\times$ & $x$ & $\sqrt{ }$ & $\sqrt{ }$ & $\times$ & $\times$ & $\times$ & $\sqrt{ }$ & $\sqrt{ }$ \\
\hline & Trip & $x$ & $x$ & $x$ & $x$ & $x$ & $x$ & $x$ & $\times$ & $x$ & $x$ \\
\hline & Unexpected step-down & $x$ & $x$ & $x$ & $x$ & $x$ & $x$ & $x$ & $x$ & $\sqrt{ }$ & $\sqrt{ }$ \\
\hline & Carrying load & $\sqrt{ }$ & $\sqrt{ }$ & $\sqrt{ }$ & $\sqrt{ }$ & $\sqrt{ }$ & $\sqrt{ }$ & $\sqrt{ }$ & $\sqrt{ }$ & $\sqrt{ }$ & $\sqrt{ }$ \\
\hline \multirow[t]{4}{*}{5} & Slip & $x$ & $x$ & $x$ & $x$ & $x$ & $x$ & $x$ & $x$ & $x$ & $x$ \\
\hline & Trip & $x$ & $x$ & $x$ & $x$ & $\sqrt{ }$ & $x$ & $x$ & $x$ & $x$ & $x$ \\
\hline & Unexpected step-down & $x$ & $x$ & $x$ & $\sqrt{ }$ & $x$ & $x$ & $\times$ & $\times$ & $\sqrt{ }$ & $\sqrt{ }$ \\
\hline & Carrying load & $x$ & $\sqrt{ }$ & $x$ & $\sqrt{ }$ & $\sqrt{ }$ & $\times$ & $\sqrt{ }$ & $\sqrt{ }$ & $\sqrt{ }$ & $x$ \\
\hline
\end{tabular}

Note: $\times$ denotes a significant difference $(p<0.05) ; \sqrt{ }$ represents no significant difference $(p \geq 0.05) ; S T=$ Stride time; SL $=$ Stride

length; $S w P=$ Swing time; $S t P=$ Stance time; $S S T=$ Single support time; WIMU = Wearable inertial measurement unit; WIPS =

Wearable insole pressure system. 
Table 3 presents the validity results of the wearable sensing measurement systems (i.e., WIMU and WIPS) for measuring gait parameters to identify safety hazards in construction. According to Table 3, the estimated means of WIPS-based gait parameters showed similar results as compared to the reference system. In other words, there were no significant differences (all $p$-values $\geq 0.05$ ) in means between WIPS-based gait parameters and WIMU-based gait parameters. In all experimental fall risk events, the MDs between WIMU-based gait parameters and WIPS-based gait parameters are less than or equal to $0.09 \mathrm{~s}, 0.09 \mathrm{~m}, 0.07 \%, 0.09 \%$, and $0.09 \%$ for $S T, S L, S w P$, $S t P$, and $S S T$, respectively (Table 3). In addition, gait parameters such as $S T, S L$, and $S w P$ showed higher MAE between WIMU-based gait parameters and WIPS-based gait parameters in all experimental fall risk events as compared to $S t P$ and $S S T$ (Table 3). Similar results of higher MAPE and RMSE were found between WIMU-based gait parameters and WIPS-based gait parameters such as $S T, S L$, and $S w P$ in all experimental fall risk events (Table 3). For instance, the highest RMSE between WIMU-based gait parameters and WIPS-based gait parameters was $1.22 \mathrm{~s}$ in $S T$, $0.95 \%$ in $S w P, 0.57 \mathrm{~m}$ in $S L, 0.87 \%$ in $S w P$, and 0.39 s in $S T$ during normal gait, slip, trip, unexpected step-down, and carrying load events, respectively (Table 3). Lastly, the ICC (95\% CI) between WIMU-based gait parameters and WIPS-based gait parameters are all closer to 1(all ICC $\geq 0.751$ ) in each experimental fall risk event (Table 3). Overall, the results demonstrate that WIPSbased gait parameters such as $S T, S L$, and $S w P$ achieved similar findings as compared to WIPSbased gait parameters for identifying safety hazards in construction. 
Table 3. Validity analysis of gait parameters for identifying safety hazards in construction

\begin{tabular}{|c|c|c|c|c|c|c|c|c|}
\hline \multirow[t]{2}{*}{ Fall risk events } & \multirow[t]{2}{*}{ Gait parameters } & \multirow{2}{*}{$\begin{array}{l}\text { WIMU } \\
\text { Mean (SD) }\end{array}$} & \multirow{2}{*}{$\begin{array}{l}\text { WIPS } \\
\text { Mean (SD) }\end{array}$} & \multirow[t]{2}{*}{ MD } & \multirow[t]{2}{*}{ MAE } & \multirow[t]{2}{*}{ MAPE } & \multirow[t]{2}{*}{ RMSE } & \multirow[t]{2}{*}{ ICC $(95 \% \mathrm{CI})$} \\
\hline & & & & & & & & \\
\hline \multirow[t]{5}{*}{ Normal gait } & $S T(\mathrm{~s})$ & $3.30(1.21)$ & $3.28(0.29)$ & 0.02 & 0.96 & 39.48 & 1.22 & 0.751 \\
\hline & $S L(\mathrm{~m})$ & $4.35(0.23)$ & $4.27(0.09)$ & 0.09 & 0.13 & 2.96 & 0.18 & 0.819 \\
\hline & $S w P(\%)$ & $1.57(0.47)$ & $1.56(0.24)$ & 0.01 & 0.40 & 27.54 & 0.43 & 0.931 \\
\hline & $\operatorname{StP}(\%)$ & $5.58(0.19)$ & $5.49(0.30)$ & 0.09 & 0.30 & 5.44 & 0.37 & 0.844 \\
\hline & $S S T(\%)$ & $7.35(0.15)$ & $7.31(0.17)$ & 0.03 & 0.11 & 1.55 & 0.16 & 0.810 \\
\hline \multirow[t]{5}{*}{ Slip } & $S T(\mathrm{~s})$ & $1.47(0.27)$ & $1.39(0.17)$ & 0.08 & 0.30 & 19.85 & 0.33 & 0.833 \\
\hline & $S L(\mathrm{~m})$ & $2.42(0.23)$ & $2.40(0.18)$ & 0.02 & 0.18 & 7.09 & 0.22 & 0.949 \\
\hline & $S_{w P}(\%)$ & $6.28(1.09)$ & $6.25(0.16)$ & 0.03 & 0.82 & 13.61 & 0.95 & 0.979 \\
\hline & $S t P(\%)$ & $4.29(0.18)$ & $4.24(0.17)$ & 0.05 & 0.17 & 3.79 & 0.24 & 0.841 \\
\hline & $\operatorname{SST}(\%)$ & $3.35(0.30)$ & $3.32(0.24)$ & 0.03 & 0.21 & 6.03 & 0.26 & 0.765 \\
\hline \multirow[t]{5}{*}{ Trip } & $S T(\mathrm{~s})$ & $1.51(0.29)$ & $1.46(0.28)$ & 0.05 & 0.06 & 3.89 & 0.06 & 0.988 \\
\hline & $S L(\mathrm{~m})$ & $0.29(0.16)$ & $0.22(0.09)$ & 0.07 & 0.34 & 50.52 & 0.57 & 0.923 \\
\hline & $S w P(\%)$ & $7.32(0.24)$ & $7.25(0.16)$ & 0.07 & 0.20 & 2.77 & 0.24 & 0.899 \\
\hline & $S t P(\%)$ & $5.58(0.19)$ & $5.55(0.39)$ & 0.03 & 0.11 & 7.36 & 0.42 & 0.793 \\
\hline & $\operatorname{SST}(\%)$ & $3.44(0.23)$ & $3.41(0.35)$ & 0.04 & 0.26 & 7.36 & 0.34 & 0.899 \\
\hline \multirow[t]{5}{*}{ Unexpected step down } & $S T(\mathrm{~s})$ & $1.36(0.39)$ & $1.27(0.14)$ & 0.09 & 0.29 & 19.33 & 0.36 & 0.831 \\
\hline & $S L(\mathrm{~m})$ & $0.74(0.10)$ & $0.69(0.26)$ & 0.05 & 0.19 & 24.15 & 0.29 & 0.969 \\
\hline & $S w P(\%)$ & $5.35(0.92)$ & $5.32(0.13)$ & 0.02 & 0.71 & 13.96 & 0.87 & 0.806 \\
\hline & $\operatorname{StP}(\%)$ & $6.45(0.25)$ & $6.38(0.34)$ & 0.07 & 0.21 & 3.31 & 0.24 & 0.794 \\
\hline & $S S T(\%)$ & $2.32(0.16)$ & $2.24(0.21)$ & 0.09 & 0.16 & 6.98 & 0.18 & 0.861 \\
\hline \multirow[t]{5}{*}{ Carrying load } & $S T(\mathrm{~s})$ & $1.29(0.30)$ & $1.28(0.28)$ & 0.01 & 0.37 & 28.24 & 0.39 & 0.942 \\
\hline & $S L(\mathrm{~m})$ & $2.64(0.16)$ & $2.62(0.19)$ & 0.02 & 0.25 & 9.44 & 0.26 & 0.824 \\
\hline & $S w P(\%)$ & $1.53(0.29)$ & $1.47(0.32)$ & 0.06 & 0.21 & 12.75 & 0.26 & 0.764 \\
\hline & $S t P(\%)$ & $4.44(0.20)$ & $4.42(0.18)$ & 0.02 & 0.22 & 5.03 & 0.27 & 0.834 \\
\hline & SST (\%) & $6.49(0.16)$ & $6.45(0.33)$ & 0.04 & 0.27 & 4.08 & 0.34 & 0.842 \\
\hline
\end{tabular}

Note: $S T=$ Stride time; $S L=$ Stride length; $S w P=$ Swing time; $S t P=$ Stance time; $S S T=$ Single support time; SD = Standard deviation; WIMU = Wearable inertial measurement unit; WIPS = Wearable insole pressure system; MD = Mean difference; MAE = Mean absolute error; MAPE = Mean absolute percentage error; $\mathrm{RMSE}=$ Root mean square error; and ICC $=$ Intraclass correlation coefficient. 
Figure 3 (a) to (e) illustrates mean and standard deviation of test-retest reliability analysis of the wearable sensing measurement systems (i.e., WIMU and WIPS) for measuring gait parameters to identify safety hazards in construction. The results found no significant differences (all $p$-values $\geq$ 0.05 ) in means of test-retest reliability analysis in all measured gait parameters either by using WIMU or WIPS. In all experimental events, the MDs of test-retest reliability analysis in each WIPS-based gait parameters are $S T( \pm 0.2 \mathrm{~s})$, SL $( \pm 0.08 \mathrm{~m}), S w P( \pm 0.05 \%), S t P( \pm 0.1 \%)$, and $S S T( \pm 0.05 \%)$ as compared to $S T( \pm 0.02 \mathrm{~s}), S L( \pm 0.06 \mathrm{~m}), S w P( \pm 0.05 \%), S t P( \pm 0.07 \%)$, and $S S T( \pm 0.05 \%)$ in the reference system. In summary, similar reliability results were found between WIPS-based gait parameters and WIMU-based gait parameters. Table 4 shows the ICC of testretest reliability for WIMU-based gait parameters or WIPS-based gait parameters for identifying safety hazards in construction. This analysis was further conducted to measure the reliability of gait parameters measured by using WIPS or the reference system to identify safety hazards. As shown in Table 4, all measured gait parameters had test-retest reliability (all ICC $\geq 0.910$ ) closer to 1 , indicating good reliability of using WIPS-based gait parameters for identifying safety hazards. 


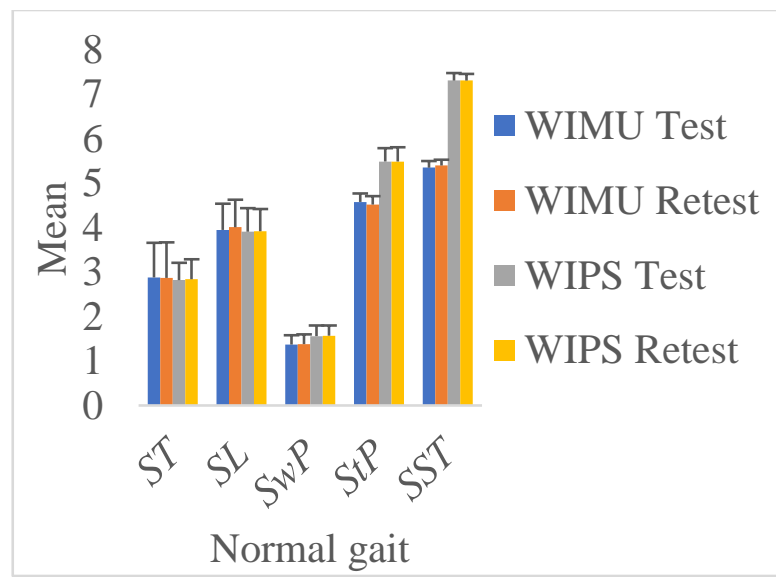

(a)

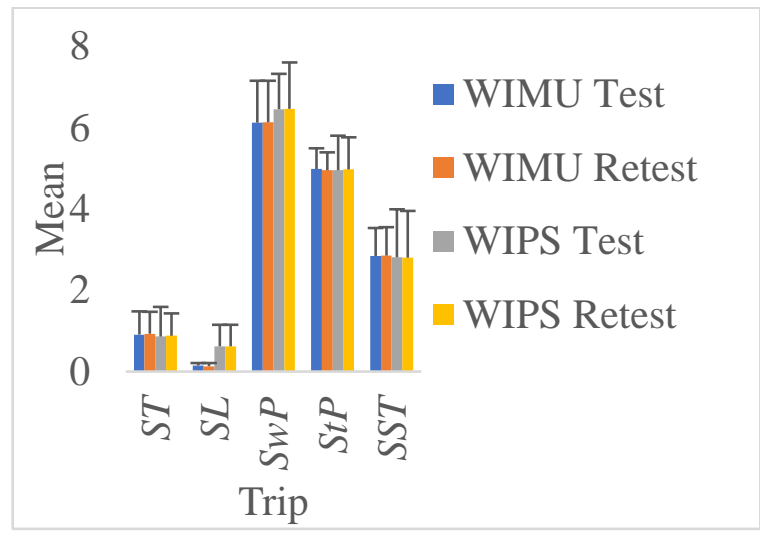

(c)

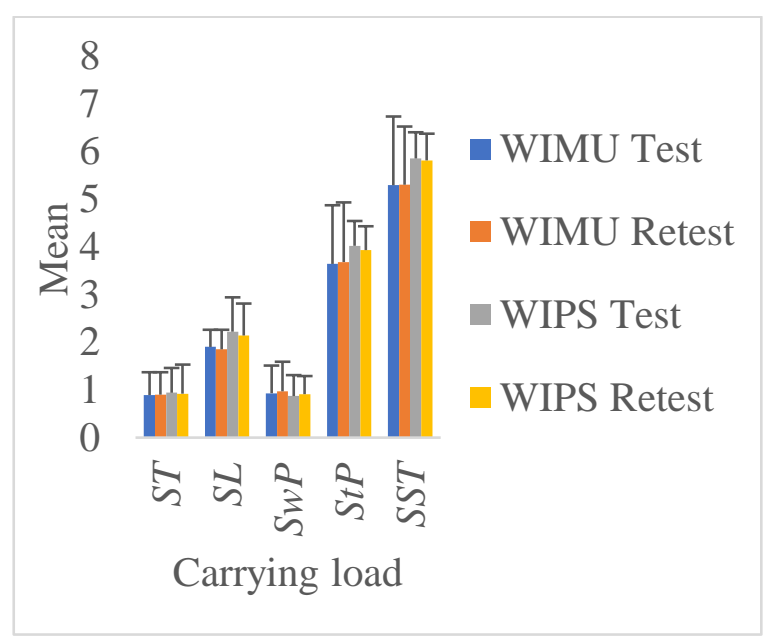

(e)

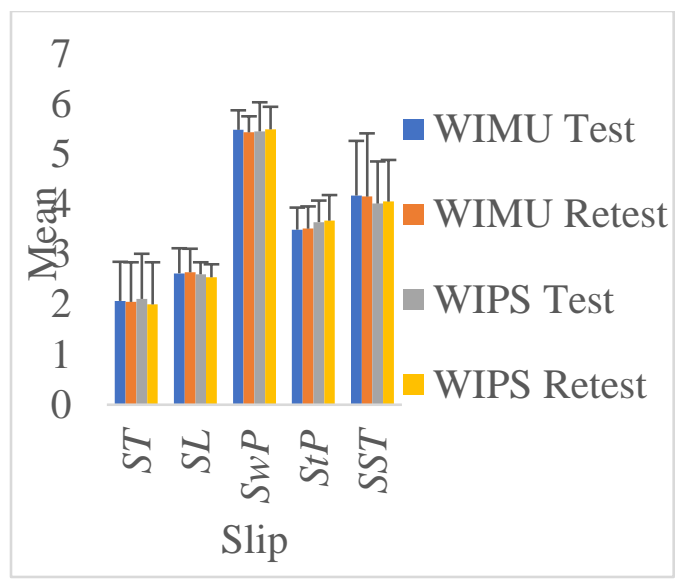

(b) (d)

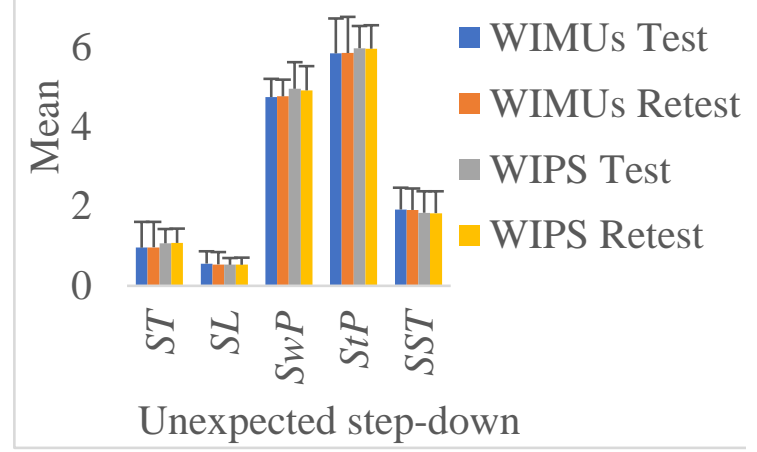

Fig. 3. Mean and standard deviation of test-retest reliability analysis for WIMU-based gait parameters and WIPS-based gait parameters: (a) Normal gait; (b) Slip; (c) Trip; (d) Unexpected step-down; and (e) Carrying load. Error bars = Standard deviation. 
Table 4. Test-retest reliability analysis of gait parameters for identifying safety hazards in construction

\begin{tabular}{|c|c|c|c|c|c|c|c|c|c|c|}
\hline \multirow[t]{3}{*}{ Fall risk events } & \multicolumn{10}{|c|}{ Intraclass correlation coefficient } \\
\hline & \multicolumn{5}{|c|}{ WIMU-based gait parameters } & \multicolumn{5}{|c|}{ WIPS-based gait parameters } \\
\hline & $S T(\mathbf{s})$ & $S L(\mathrm{~m})$ & SwP (\%) & $S t P(\%)$ & SST (\%) & $S T(\mathbf{s})$ & $S L(\mathbf{m})$ & SwP $(\%)$ & $S t P(\%)$ & $S S T(\%)$ \\
\hline Normal gait & 0.997 & 0.988 & 0.996 & 0.998 & 0.998 & 0.999 & 0.996 & 0.999 & 0.999 & 0.996 \\
\hline Slip & 0.998 & 0.999 & 0.998 & 0.997 & 0.910 & 0.999 & 0.998 & 0.999 & 0.998 & 0.957 \\
\hline Trip & 0.994 & 0.998 & 0.999 & 0.912 & 0.999 & 0.955 & 0.991 & 0.997 & 0.999 & 0.998 \\
\hline Unexpected step down & 0.999 & 0.998 & 0.989 & 0.999 & 0.997 & 0.997 & 0.999 & 0.996 & 0.998 & 0.980 \\
\hline Carrying load & 0.997 & 0.998 & 0.999 & 0.998 & 0.999 & 0.998 & 0.998 & 0.999 & 0.958 & 0.999 \\
\hline
\end{tabular}

Note: $S T=$ Stride time; $S L=$ Stride length; $S w P=$ Swing time; $S t P=$ Stance time; $S S T=$ Single support time; WIMU = Wearable

inertial measurement unit; WIPS = Wearable insole pressure system. 


\section{Discussion}

Falls are a leading cause of non-fatal injuries among occupational workers. Changes in participants' gait patterns have been demonstrated to provide useful data source to assess fall risks in clinical, sports and rehabilitation occupations (Crea et al., 2014; Leardini et al., 2014; Norris et al., 2014; Shull et al., 2014; Braun et al., 2015). In the realm of construction, most of the existing studies had utilized WIMUs (Kim et al., 2016; Yang et al., 2017; Yang and Ahn, 2019) and WIPS (AntwiAfari and Li, 2018g; Antwi-Afari et al., 2018e; Antwi-Afari et al., 2020b) to collect participants' gait patterns for preventing non-fatal fall injuries. However, there is a missing research gap on the performance of measuring WIPS-based gait parameters for identifying safety hazards in construction as compared to WIMU-based gait parameters. As an attempt to fill this research gap, the current study aimed to examine the validity and reliability of measuring WIPS-based gait parameters for identifying safety hazards in construction environments when compared to WIMUbased gait parameters (i.e., reference system). The results revealed significant differences in gait parameters between normal gait and each hazardous event. In addition, the performance results indicated that WIPS-based gait parameters were comparable to the reference system for identifying safety hazards. Overall, the findings of this study contribute to developing an automated WIPS, that could be useful for mitigating the risk of developing non-fatal fall injuries on construction sites.

In this current study, five gait parameters were first investigated to examine the statistically significant differences between a normal gait and each hazardous event. The results found significant differences in either WIPS-based gait parameters or WIMU-based gait parameters for distinguishing between normal gait and hazardous events. More specifically, WIPS-based gait 
parameters or WIMU-based gait parameters such as $S T, S L$, and $S w P$ showed unique gait patterns for distinguishing between normal gait and hazardous events. These results indicated that stride time, stride length, and swing time could be used to capture workers' gait patterns when they are exposed to safety hazards on construction sites. Given the relationship between gait patterns and the presence of safety hazards, safety managers could use workers' gait movements to identify safety hazards and further assess fall risk events on construction sites. Also, the collected gait patterns could provide great potential for automated recognition of workers' activities and productivity analyses. In summary, the findings of this study have demonstrated the capability of using WIPS-based gait parameters for distinguishing safety hazards in the construction environment in comparison to WIMU-based gait parameters.

The primary research motivation of this study was to examine the validity and reliability of WIPSbased gait parameters for identifying safety hazards in construction comparable to WIMU-based gait parameters. The results showed no significant differences in means between WIPS-based gait parameters and the reference system. Besides, gait parameters such as $S T, S L$, and $S w P$ showed higher MAE, MAPE, and RMSE between WIMU-based gait parameters and WIPS-based gait parameters in all experimental fall risk events. Furthermore, the ICC (95\% CI) between WIMUbased gait parameters and WIPS-based gait parameters are all closer to 1 (all ICC $\geq 0.751$ ) in each experimental fall risk event. WIPS could be considered as a valid wearable sensing system for identifying safety hazards since the collected WIPS-based gait parameters achieved good performance as compared to WIMU-based gait parameters. Similarly, the test-retest reliability analysis was conducted to confirm that the observed differences in measuring gait parameters were not due to measurement errors. The MDs between WIPS-based gait parameters and WIMU-based 
gait parameters found no significant differences in all experimental fall risk events. Lastly, the test-retest reliability showed a good correlation (all ICC $\geq 0.910$ ), confirming the reliability of the WIPS-based gait parameters for identifying safety hazards in a construction environment. Taken together, the results of this study demonstrate the validity and reliability of measuring WIPS-based gait parameters for identifying safety hazards on construction sites.

Previous studies in clinical, sports and rehabilitation settings have demonstrated the performance of WIPS-based gait parameters (Braun et al., 2015; Jagos et al., 2017; Arafsha et al., 2018). Although these existing studies provided useful gait parameters in application areas such as assessing fall risks, automated gait monitoring, posture and human activity recognition, and energy expenditure estimation, some drawbacks limit its application in real construction sites. For example, WIPS-based gait parameters were measured in most of these existing studies during activities of daily living and also the participants were patients with neurological disorders such as stroke, diabetes, cerebral palsy. As such, these methodological scenarios make it difficult to compare our current results to findings from previous studies' applications.

Loiret et al. (2019) demonstrated the validity of Loadsol® insoles versus force plates in quantifying normal ground reaction force and gait asymmetry during gait at three different speeds in transfemoral amputees. These authors found normalized RMSEs for the normal ground reaction forces were $6.6 \pm 2.3 \%$ and $8.9 \pm 3.8 \%$, and correlation coefficients were 0.91 and 0.95 for the prosthetic and intact limb, respectively. Their findings support the relevance of using such insoles for visual and audio feedback in clinical and rehabilitation settings. Compared to this current study, we achieved the highest RMSEs of $1.22 \mathrm{~s}$ in $S T, 0.95 \%$ in $S w P, 0.57 \mathrm{~m}$ in $S L, 0.87 \%$ in $S w P$, and 
0.39s in $S T$ during normal gait, slip, trip, unexpected step-down, and carrying load events, respectively. In addition, the ICCs $(95 \% \mathrm{CI})$ were between 0.751 to 0.988 (inclusive) for $S T, S L$, $S w P$ gait parameters. Since higher gait variability parameter indicates a high risk of fall accidents, the findings could collectively be useful for identifying safety hazards, thus mitigating individuals' fall risks by providing visual and audio feedback.

Another study by Arafsha et al. (2018) and Jagos et al. (2017) examined the validity of measuring gait parameters between SmartInsole Cyber-Physical System and Tekscan Strideway gait mat system, and between the eSHOE and GAITRite, respectively. Arafsha et al. (2018) reported MD between $-0.03 \mathrm{~s}$ and $0.02 \mathrm{~s}$, while Jagos et al. (2017) found MD of gait parameters between $-0.029 \mathrm{~s}$ and $0.029 \mathrm{~s}$. The MDs for $S T$ in this present study, as shown in Table 3, ranged between 0.01 to $0.09 \mathrm{~s}$, which are different from previous studies. However, it is worth mentioning that the differences may be due to the number of healthy participants who are relatively higher in these clinical studies as compared to five participants in the present study. Braun et al. (2015) investigated the validity and reliability of an OpenGo insole system with FDM-S pressure force plate system in healthy individuals on a treadmill at two different speeds. Their results showed ICC for validation and reliability were $\geq 0.796$ and $\geq 0.994$, respectively for all measured gait parameters. In the present study, the results showed similar ICC for validation (i.e., $\geq 0.751$ ) and reliability $(\geq 0.910)$ for all measured gait parameters. Although they are comparable, there are still some methodological differences. First, Braun et al. (2015) conducted a normal gait on a treadmill at two different speeds. The current study conducted five fall risk events which may lead to nonfatal fall injuries. Second, they used 12 healthy participants (age ranges between 18 to 37 years) as compared to 5 healthy participants (age ranges between 30 to 40 years) in this present study. 
Third, these authors used FDM-S pressure force plate as a reference system as compared to WIMUs in this current study. In summary, the measured gait parameters could be useful for collecting workers' gait patterns caused by the presence of safety hazards to prevent non-fatal fall injuries on construction sites.

\section{Study limitations}

This study has some limitations. First, the participants were healthy volunteers and the experiments were conducted in a laboratory setting. Future research is warranted to recruit construction workers and conduct real-world construction site experiments. In addition, future research needs to examine the performance of the proposed approach by using virtual and augmented reality (VR/AR) applications. This could improve the experimental design and procedure by enhancing any psychological risk factors (e.g., mental workload) and potential injuries of participants. Second, the experimental events were limited to non-fatal fall hazards among construction workers. There are other risk factors such as awkward working postures, falls from a height that are frequently exposed to workers on sites. Future studies are needed to test the performance of WIPS-based gait parameters for other risk factors. In addition, future studies will need to incorporate data processing and real-time warning algorithms to enable workers' self-awareness and self-management when exposed to hazards on construction sites.

\section{Conclusions}

This study examined the validity and reliability of WIPS-based gait parameters as compared to WIMU-based gait parameters for identifying safety hazards in construction. Five fall risk events were conducted in a laboratory setting and the performance was assessed by calculating the MD,

MAE, MAPE, RMSE, and ICC of five gait parameters. The results found significant differences 
in either WIPS-based gait parameters or WIMU-based gait parameters for distinguishing between a normal gait and each hazardous event. Comparable results of MD, MAE, MAPE, and RMSE were found between WIPS-based gait parameters and the reference system. Furthermore, all measured gait parameters had validity (ICC $\geq 0.751)$ and test-retest reliability (ICC $\geq 0.910)$ closer to 1, indicating the good performance of measuring WIPS-based gait parameters for distinguishing safety hazards. Overall, the findings of this study support the relevance of developing a WIPS as a non-invasive wearable sensing technology for identifying safety hazards on construction sites, thus highlighting the usefulness of its applications for construction safety research. The findings of this study reveal that WIPS-based gait parameters can achieve a performance comparable to WIMU-based gait parameters for distinguishing safety hazards in construction. The main contribution of this study relies on examining the performance of a WIPS for identifying safety hazards in construction. As such, the present study contributes to developing a non-intrusive WIPS for identifying safety hazards in construction. In addition, this proposed approach could help to expand the use of wearable sensing technologies for mitigating non-fatal fall injuries and enhancing construction safety research.

\section{Data Availability Statement}

All data generated or analyzed that support the findings of this study are available from the corresponding author upon request.

\section{Declarations of interest}

None 


\section{Acknowledgements}

We are thankful for the financial support of the following two grants from Research Grants Council of Hong Kong: 1) "Proactive monitoring of work-related MSD risk factors and fall risks of construction workers using wearable insoles" (PolyU 152099/18E); and 2) In search of a suitable tool for proactive physical fatigue assessment: an invasive to non-invasive approach. (PolyU 15204719/18E). Special thanks are given to Mr Wong Chun Fai for assisting the experimental setup and all our participants involved in this study.

\section{References}

Akhavian, R. and Behzadan, A. H. (2016), “Smartphone-Based Construction Workers' Activity Recognition and Classification”, Automation in Construction, Vol. 71, No. 2, pp. 198-209. DOI: https://doi.org/10.1016/j.autcon.2016.08.015.

Albert, A., Hallowell, M. R. and Kleiner, B. M. (2014b), "Experimental Field Testing of a Real-Time Construction Hazard Identification and Transmission Technique", Construction Management and Economics, Vol. 32, No. 10, pp. 1000-1016. DOI: https://doi.org/10.1080/01446193.2014.929721.

Albert, A., Hallowell, M. R., Kleiner, B., Chen, A. and Golparvar-Fard, M. (2014a), "Enhancing Construction Hazard Recognition with High-Fidelity Augmented Virtuality", Journal of Construction Engineering Management, Vol. 140, No. 7, pp. 4014024. DOI: https://doi.org/10.1061/(ASCE)CO.1943-7862.0000860.

Aminian, K., Najafi, B., Büla, C., Leyvraz, P. F. and Robert, P. (2002), "Spatio-temporal Parameters of Gait Measured by an Ambulatory System Using Miniature Gyroscopes", Journal of Biomechanics, Vol. 35, No. 5, pp. 689-699. DOI: https://doi.org/10.1016/S0021-9290(02)00008-8.

Antwi-Afari, M. F. (2019), "Evaluation of Biomechanical Risk Factors for Work-Related Musculoskeletal Disorders and Fall Injuries among Construction Workers”, Ph.D. Thesis, Department of Building and Real Estate, The Hong Kong Polytechnic University. 
Antwi-Afari, M. F. and Li, H. (2018g), "Fall Risk Assessment of Construction Workers Based on Biomechanical Gait Stability Parameters Using Wearable Insole Pressure System”, Advanced Engineering Informatics, Vol. 38, pp. 683-694. DOI: https://doi.org/10.1016/j.aei.2018.10.002.

Antwi-Afari, M. F., Li, H., Anwer, S., Yevu, S. K., Wu, Z., Antwi-Afari, P., and Kim, I. (2020b), “Quantifying Workers' Gait Patterns to Identify Safety Hazards in Construction Using a Wearable Insole Pressure System", Safety Science. Vol. 129, pp. 104855. DOI: https://doi.org/10.1016/j.ssci.2020.104855.

Antwi-Afari, M. F., Li, H., Edwards, D. J., Pärn, E. A., Owusu-Manu, D., Seo, J. and Wong, A. Y. L. (2018a), "Identification of Potential Biomechanical Risk Factors for Low Back Disorders During Repetitive Rebar Lifting”, Construction Innovation: Information, Process, Management, Vol. 18, No. 2. DOI: https://doi.org/10.1108/CI-05-2017-0048.

Antwi-Afari, M. F., Li, H., Luo, X. E., Edwards, D. J., Owusu-Manu, D. and Darko, A. (2019c), “Overexertion-related construction workers' activity recognition and ergonomic risk assessment based on wearable insole pressure system", Proceedings of $8^{\text {th }}$ West Africa Built Environment Research (WABER) Conference, Accra, Ghana, August 5-7, 2019. Available via: https://www.researchgate.net/publication/335570297.

Antwi-Afari, M. F., Li, H., Seo, J. and Wong, A. Y. L. (2018e), "Automated Detection and Classification of Construction Workers' Loss of Balance Events Using Wearable Insole Pressure Sensors", Automation in Construction, Vol. 96, pp. 189-199. DOI: https://doi.org/10.1016/j.autcon.2018.09.010.

Antwi-Afari, M. F., Li, H., Umer, W., Yu, Y., and Xing, X. (2020a), "Construction Activity Recognition and Ergonomic Risk Assessment Using a Wearable Insole Pressure System”, Journal of Construction Engineering and Management, Vol. 146, No. 7, pp. 04020077. DOI: https://doi.org/10.1061/(ASCE)CO.1943-7862.0001849.

Antwi-Afari, M. F., Li, H., Wong, J. K. W., Oladinrin, O. T., Ge, J. X., Seo, J. and Wong, A. Y. L. (2019a), "Sensing and Warning-Based Technology Applications to Improve Occupational Health and Safety in the Construction Industry: A Literature Review", Engineering, Construction and Architectural Management, Vol. 26, No. 8, pp. 1534-1552. DOI: https://doi.org/10.1108/ECAM-05-2018-0188. 
Antwi-Afari, M. F., Li, H., Yu, Y. and Kong, L. (2018f), "Wearable Insole Pressure System for Automated Detection and Classification of Awkward Working Postures in Construction Workers", Automation in Construction, Vol. 96, pp. 433-441. DOI: https://doi.org/10.1016/j.autcon.2018.10.004.

Arafsha, F., Hanna, C., Aboualmagd, A., Fraser, S. and El Saddik, A. (2018), "Instrumented Wireless Smartinsole System for Mobile Gait Analysis: A Validation Pilot Study with Tekscan Strideway", Journal of Sensor and Actuator Networks, Vol. 7, No. 3, pp. 36. DOI: https://doi.org/10.3390/jsan7030036.

Bentley, T. A., Hide, S., Tappin, D., Moore, D., Legg, S., Ashby, L. and Parker, R. (2006), "Investigating Risk Factors for Slips, Trips and Falls in New Zealand Residential Construction Using Incident-Centred and Incident-Independent Methods", $\begin{array}{llllll}\text { Ergonomics, Vol. } & 49, \quad \text { No. } & \text { 1, }\end{array}$ https://doi.org/10.1080/00140130612331392236.

Braun, B. J., Veith, N. T., Hell, R., Döbele, S., Roland, M., Rollmann, M., Holstein, J. and Pohlemann, T. (2015), "Validation and Reliability Testing of a New, Fully Integrated Gait Analysis Insole", Journal of Foot and Ankle Research, Vol. 8, No. 1, pp. 54. DOI: https://doi.org/10.1186/s13047-015-0111-8.

Bureau of Labor Statistics (BLS) (2017), "Injuries, Illnesses, and Fatalities", Available at: https://www.bls.gov/iif/ (Accessed 20 February 2020).

Choi, S., Cho, H., Kang, B., Lee, D. H., Kim, M. J. and Jang, S. H. (2015), "Slip-Related Changes in Plantar Pressure Distribution, and Parameters for Early Detection of Slip Events", Annals of Rehabilitation Medicine, Vol. 39, No. 6, pp. 897-904. DOI: https://doi.org/10.5535/arm.2015.39.6.897.

Crea, S., Donati, M., De Rossi, S., Oddo, C. and Vitiello, N. (2014), “A Wireless Flexible Sensorized Insole for Gait Analysis", Sensors, Vol. 14, No. 1, pp. 1073-1093. DOI: https://doi.org/10.3390/s140101073.

Earnest, G. S. and Branche, C. M. (2016), Knowledge Gaps and Emerging Issues for Fall Control in Construction, Fall Prevention and Protection, Taylor \& Francis, Boca Raton, FL. ISBN: 1-4822-1714-7.

Edirisinghe, R. (2019), "Digital Skin of the Construction Site: Smart Sensor Technologies Towards the Future Smart Construction Site", Engineering, Construction and 
Architectural Management, Vol. 26, No. 2, pp. 184-223. DOI: https://doi.org/10.1108/ECAM-04-2017-0066.

Fang, D. P., Huang, X. Y. and Hinze, J. (2004), "Benchmarking Studies on Construction Safety Management in China", Journal of Construction Engineering and Management, Vol. 130, No. 3, pp. 424-432. DOI: https://doi.org/10.1061/(ASCE)0733-9364(2004)130:3(424).

Gauchard, G., Chau, N., Mur, J. M. and Perrin, P. (2001), "Falls and Working Individuals: Role of Extrinsic and Intrinsic Factors", Ergonomics, Vol. 44, No.14, pp. 1330-1339, DOI: http://dx.doi.org/10.1080/00140130110084791.

Han, S. and Lee, S. (2013), "A Vision-Based Motion Capture and Recognition Framework for Behavior-Based Safety Management", Automation in Construction, Vol. 35, pp. 131-141. DOI: http://dx.doi.org/10.1016/j.autcon.2013.05.001.

Hausdorff, J. M., Cudkowicz, M. E., Firtion, R., Wei, J. Y. and Goldberger, A. L. (1998), “Gait Variability and Basal Ganglia Disorders: Stride-To-Stride Variations of Gait Cycle Timing in Parkinson's Disease and Huntington's Disease", Movement Disorders, Vol. 13, No. 3, pp. 428-437. DOI: https://doi.org/10.1002/mds.870130310.

Jagos, H., Pils, K., Haller, M., Wassermann, C., Chhatwal, C., Rafolt, D. and Rattay, F. (2017), "Mobile Gait Analysis via eSHOEs Instrumented Shoe Insoles: A Pilot Study for Validation Against the Gold Standard GAITRite®”, Journal of Medical Engineering \& $\begin{array}{llllll}\text { Technology, Vol. } & 41, & \text { No. } & 5, & \text { pp. } & \text { 375-386. }\end{array}$ https://doi.org/10.1080/03091902.2017.1320434.

Kim, H., Ahn, C. R. and Yang, K. (2016), "Identifying Safety Hazards Using Collective Bodily Responses of Workers", Journal of Construction Engineering and Management, Vol. 143, No. 2, pp. 04016090. DOI: https://doi.org/10.1061/(ASCE)CO.1943-7862.0001220.

Kim, K., Kim, H., and Kim, H. (2017), "Image-Based Construction Hazard Avoidance System Using Augmented Reality in Wearable Device", Automation in construction, Vol. 83, pp. 390-403. DOI: https://doi.org/10.1016/j.autcon.2017.06.014.

Kong, L., Li, H., Yu, Y., Luo, H., Skitmore, M. and Antwi-Afari, M. F. (2018), "Quantifying the Physical Intensity of Construction Workers, A Mechanical Energy Approach", Advanced Engineering Informatics, Vol. 38, pp. 404-419. DOI: https://doi.org/10.1016/j.aei.2018.08.005. 
Leardini, A., Lullini, G., Giannini, S., Berti, L., Ortolani, M. and Caravaggi, P. (2014), "Validation of the Angular Measurements of a New Inertial-Measurement-Unit Based Rehabilitation System: Comparison with State-Of-The-Art Gait Analysis”, Journal of Neuroengineering and Rehabilitation, Vol. 11, No. 1, pp. 136. DOI: https://doi.org/10.1186/1743-0003-11136.

Lipscomb, H. J., Glazner, J. E., Bondy, J., Guarini, K. and Lezotte, D. (2006), “Injuries from Slips and Trips in Construction", Applied Ergonomics, Vol. 37, No. 3, pp. 267-274. DOI: http://dx.doi.org/10.1016/j.apergo.2005.07.008.

Liu, J. and Lockhart, T. E. (2013), "Local Dynamic Stability Associated with Load Carrying", Safety and Health at Work, Vol. 4, No. 1, pp. 46-51. DOI: https://doi.org/10.5491/SHAW.2013.4.1.46.

Loiret, I., Villa, C., Dauriac, B., Bonnet, X., Martinet, N., Paysant, J. and Pillet, H. (2019), “Are Wearable Insoles a Validated Tool for Quantifying Transfemoral Amputee Gait Asymmetry?", Prosthetics and Orthotics International, Vol. 43, No. 5, pp. 492-499. DOI: https://doi.org/10.1177/0309364619865814.

Norris, M., Anderson, R. and Kenny, I. C. (2014), "Method Analysis of Accelerometers and Gyroscopes in Running Gait: A Systematic Review, Proceedings of the Institution of Mechanical Engineers, Part P: Journal of Sports Engineering and Technology, Vol. 228, No. 1, pp. 3-15. DOI: https://doi.org/10.1177/1754337113502472.

Park, J., Marks, E., Cho, Y. K. and Suryanto, W. (2015), "Performance Test of Wireless Technologies for Personnel and Equipment Proximity Sensing in Work Zones”, Journal of Construction Engineering and Management, Vol. 142, No. 1, pp. 04015049. DOI: https://doi.org/10.1061/(ASCE)CO.1943-7862.0001031.

Ray, S. J. and Teizer, J. (2012), "Real-Time Construction Worker Posture Analysis for Ergonomics Training”, Advanced Engineering Informatics, Vol. 26, No. 2, pp. 439-455. DOI: http://dx.doi.org/10.1016/j.aei.2012.02.011.

Rozenfeld, O., Sacks, R., Rosenfeld, Y. and Baum, H. (2010), “Construction Job Safety Analysis”, Safety Science, Vol. 48, No. 4, pp. 491-498. DOI: https://doi.org/10.1016/j.ssci.2009.12.017.

Shull, P. B., Jirattigalachote, W., Hunt, M. A., Cutkosky, M. R. and Delp, S. L. (2014), “Quantified Self and Human Movement: A Review on the Clinical Impact of Wearable Sensing and 
Feedback for Gait Analysis and Intervention”, Gait \& posture, Vol. 40, No. 1, pp. 11-19. DOI: https://doi.org/10.1016/j.gaitpost.2014.03.189.

Teizer, J., Allread, B. S., Fullerton, C. E. and Hinze, J. (2010), “Autonomous Pro-Active RealTime Construction Worker and Equipment Operator Proximity Safety Alert System”, Automation in Construction, Vol. 19, No. 5, pp. 630-640. DOI: http://dx.doi.org/10.1016/j.autcon.2010.02.009.

Valero, E., Sivanathan, A., Bosché, F. and Abdel-Wahab, M. (2017), “Analysis of Construction Trade Worker Body Motions Using a Wearable and Wireless Motion Sensor Network", Automation in Construction, Vol. 83, pp. 48-55. DOI: https://doi.org/10.1016/j.autcon.2017.08.001.

Van Eerd, D., Hogg-Johnson, S., Mazumder, A., Cole, D., Wells, R. and Moore, A. (2009), “Task Exposures in an Office Environment: A Comparison of Methods”, Ergonomics, Vol. 52, No. 10, pp. 1248-1258. DOI: https://doi.org/10.1080/00140130903023683.

Wang, J. and Razavi, S. N. (2016), "Low False Alarm Rate Model for Unsafe-Proximity Detection in Construction", Journal of Computing in Civil Engineering, Vol. 30, No. 2, pp. 1-13. DOI: http://dx.doi.org/10.1061/(ASCE)CP.1943-5487.0000470.

Yang, K., Ahn, C. R. and Kim, H. (2019), "Validating Ambulatory Gait Assessment Technique for Hazard Sensing in Construction Environments", Automation in Construction, Vol. 98, pp. 302-309. DOI: https://doi.org/10.1016/j.autcon.2018.09.017.

Yang, K., Ahn, C. R., Vuran, M. C. and Kim, H. (2017), “Collective Sensing of Workers' Gait Patterns to Identify Fall Hazards in Construction”, Automation in Construction, Vol. 82, pp. 166-178. DOI: https://doi.org/10.1016/j.autcon.2017.04.010.

Yang, K. and Ahn, C. R. (2019), "Inferring Workplace Safety Hazards from the Spatial Patterns of Workers' Wearable Data”, Advanced Engineering Informatics, Vol. 41, pp. 100924. DOI: https://doi.org/10.1016/j.aei.2019.100924.

Yuan, C., Li, S., and Cai, H. (2017), "Vision-Based Excavator Detection and Tracking Using Hybrid Kinematic Shapes and Key Nodes", Journal of Computing in Civil Engineering, Vol. $\quad 31, \quad$ No. 1, pp. $04016038 . \quad$ DOI: https://doi.org/10.1061/(ASCE)CP.1943-5487.0000602. 
Yoon, H. Y. and Lockhart, T. E. (2006), "Non-fatal Occupational Injuries Associated with Slips and Falls in the United States", International Journal of Industrial Ergonomics, Vol. 36, pp. 83-92. DOI: https://doi.org/10.1016/j.ergon.2005.08.005.

Zhang, S., Teizer, J., Lee, J. K., Eastman, C. M. and Venugopal, M. (2013), “Building Information Modeling (BIM) and Safety: Automatic Safety Checking of Construction Models and Schedules", Automation $\quad$ in $\quad$ Construction, Vol. 29, $\quad$ pp. 183-195. DOI: https://doi.org/10.1016/j.autcon.2012.05.006.

Zou, P. X. and Zhang, G. (2009), "Comparative Study on the Perception of Construction Safety Risks in China and Australia", Journal of Construction Engineering and Management, Vol. 135, No. 7, pp. 620-627. DOI: https://doi.org/10.1061/(ASCE)CO.1943-7862.0000019. 